\title{
PARLAYING STUDENTS' WORK EXPERIENCE INTO PRACTICE-ORIENTED ESP
}

\author{
Eric Koenig ${ }^{1}$, Katherine Guertler ${ }^{2}$ \\ ${ }^{1}$ Technische Hochschule Nürnberg Georg Simon Ohm \\ Phone: +49 931 5880-1743, E-Mail: eric.koenig@ @th-nuernberg.de \\ ${ }^{2}$ Ostbayerische Technische Hochschule Regensburg \\ Phone: +49 941 943-1324, E-Mail: katherine.guertler@oth-regensburg.de
}

\begin{abstract}
Instructors of English for Special Purposes often describe the challenge of determining which specific content and competencies to address in their courses. After all, it is the focus on technical subject matter which students expect to differentiate engineering ESP from standard EFL. Yet ESP instructors, who frequently have a background in fields such as applied linguistics or education, often receive little input from technical specialists as to which specialist topics are most relevant to their target domain.

Our research indicates that ESP instructors in higher education can leverage a valuable resource to enrich teaching effectiveness: students who have already gained professional experience. As part of a longitudinal study at two universities of applied sciences (UAS) in southern Germany, engineering students at the beginning of their first semester of compulsory technical English participate in an online survey. The course participants provide relevant biographical information such as work experience and evaluate the perceived importance of a selection of skills and applications for a Technical English course.

The surveys, administered in October 2016 and October 2017 and encompassing nearly 1000 respondents, provide compelling insights. Analysis reveals conclusive correlations between the perceived importance of course components and students' declared level of previous work experience. Listening comprehension, reading comprehension, process description, and test and measurement are topics whose importance correlates positively with work experience level. In addition, there are clear trends relating work experience level with the importance of the reading and writing of technical documents as well as communication and interaction.

This data provides empirically-founded criteria for selecting the topics to include in the scope of a Technical English course for engineers, informed by the judgment of students with occupational experience. Additionally, recognizing that students with work experience have legitimate practitioner credibility allows instructors to identify and select relevant subject matter in concordance with experienced students' learning objectives. ESP learners will profit greatly from cultivating skills with proven practical applicability.
\end{abstract}

Key words: ESP curricula, work experience, Technical English, ESP practitioners

\section{INTRODUCTION}

The primary distinguishing feature between a general English as a foreign language (EFL) and English for special purposes (ESP) course is the eponymous domain of specialization. 
The students in an ESP course are interested in acquiring the communicative skills required in a specific professional environment. To be effective, an ESP curriculum must be designed in conjunction with the learners' target professional application (Rahman 2015).

A central challenge for the ESP instructor is identifying what the learners' real-world needs are. In tertiary education, this can be difficult for instructors who are trained in fields such as language acquisition or educational theory - but accordingly lack a technical background in the target domain - and who may not have access to domain specialists or practitioners in industry. A longitudinal study at two universities of applied sciences (UAS) in southern Germany promotes a resource which may be more readily accessed, namely students with previous professional experience.

The students in ESP courses at UAS display a high degree of heterogeneity with respect to their biographies and English competencies (Guertler and Koenig 2018 in press). Many of the students in Germany - and ostensibly in other nations as well already have professional experience, often in occupations closely related to their field of study. This first-hand experience can serve as a valuable guideline to instructors in developing relevant curricula.

Results from this longitudinal study identify distinct differences in topic prioritization between experienced and inexperienced students. Further, they indicate that experienced students value a combination of transaction-oriented and interpersonal skills. Proper consideration of this insight can help the ESP instructor optimize their curricula to reflect elements prized by practitioners and thus provide the communicative skills most applicable in the technical workplace.

\section{PROCEDURE}

To determine whether a relationship between work experience and perceived English language needs exists among engineering students, the authors began in 2016 to conduct an annual online survey of their respective students. The participants are undergraduate engineering majors enrolled in Technical English courses at a UAS in Bavaria, Germany, either the Technische Hochschule Nürnberg or the Ostbayerische Technische Hochschule Regensburg.

Within the scope of the survey, students provide relevant biographical information such as the duration and level of their work experience. The possible work experience categories included as choices in the survey, presented here in order of increasing responsibility, are:

- a part-time job,

- an internship,

- an apprenticeship,

- a wage position,

- a salaried position, and

- self-employment.

Multiple answers are possible to reflect the diverse range of learner biographies.

The participating students are also asked to evaluate the perceived importance of a selection of skills and applications for a Technical English course. The survey presents the participants with an initial list of language elements compiled by the authors based on impressions from their teaching experience in Technical English. The instructions to the participants were to rate each element on a sliding rating scale with regard to its 
importance for a Technical English course. The slider position was subsequently translated into a numerical value from zero to ten.

The core language elements included for evaluation were:

- grammar,

- listening comprehension,

- reading comprehension,

- written expression, and

- verbal expression,

as well as more technically oriented topics:

- technical vocabulary,

- process description,

- test and measurement,

- technical documents, and

- mathematical expressions,

along with general interpersonal language competencies:

- quality and problem-solving, and

- communication and interaction.

The consolidated results from the surveys were evaluated using IBM's SPSS statistical analysis software.

\section{RESULTS}

To date, the survey has been administered in October 2016 and again in October 2017. A total of 909 participants have completed the survey, yielding a completion rate of 86.9 percent. The average age of the respondents was 21.64 years $(\sigma=3.03, N=902)$ and at the time of the survey they reported having received an average of 8.45 years $(\sigma=2.35$, $N=909$ ) of English instruction.

Of these respondents, 90.5 percent indicated they had some form of work experience. A breakdown of the types of work experience reported by respondents is displayed in Figure 1. The number of participants who reported having been self-employed was

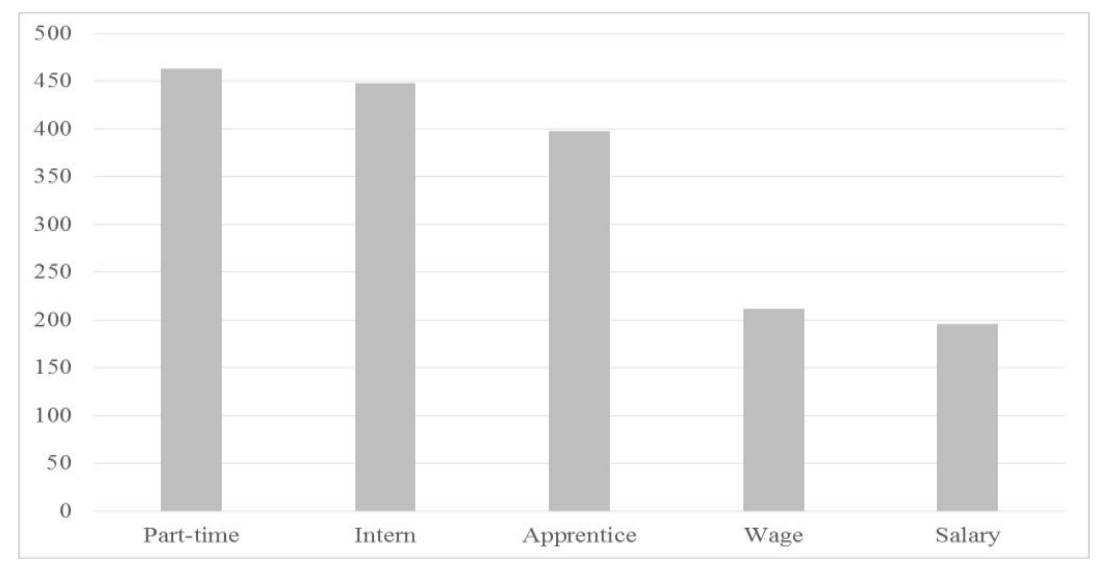

Fig. 1 Number of respondents per type of work experience $(\mathrm{N}=909)$ 
negligible $(N=22)$ and those results are therefore excluded from further analysis. The reported work duration ranged from a few months in a part-time position to several years as a salaried employee.

Key results from the importance valuation of the language elements and applications are displayed in Figure 2. The valuation averages per highest level of work experience level obtained are shown for the core language competencies grammar, listening, reading, writing and speaking. Respondents universally ranked the element vocabulary high and it is included in the diagram for reference. The mean values for the language modalities listening, reading and speaking are clustered relatively close to one another irrelevant of work experience level. However, the averages for the importance of writing range considerably lower across the board. Grammar is ranked at the bottom of the core language elements and appears to trend to even lower values with increased work experience level.

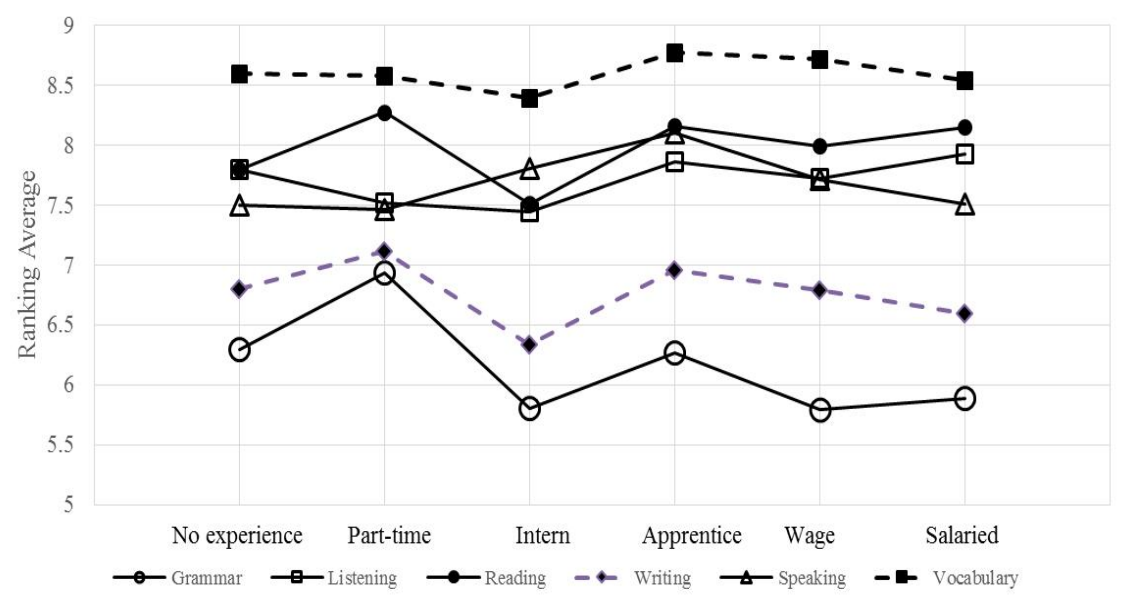

Fig. 2 Ranking averages per experience level

In Table 1, the mean valuation per element for each level of work experience is provided, and values exceeding the overall average per element are highlighted with bold font on a shaded background. These five elements were selected for representation because they are ascribed increasing importance as respondents attain work experience on a higher level of responsibility (rising from left to right in the table). In contrast, the lower responsibility work levels value these elements below the overall average.

Calculating for the Spearman correlation between the highest work level experience attained and the element rankings revealed a number of correlations, albeit relatively weak (Table 2). A negative correlation indicates that the element is attributed lower importance as the level of work experience rises, while a positive correlation means that the element grows in importance. 
Table 1 Valuation averages per work experience level

\begin{tabular}{lcccccccc}
\hline & & $\begin{array}{c}\text { No work } \\
\text { experience }\end{array}$ & Part-time & Intern & $\begin{array}{c}\text { Ap- } \\
\text { prentice }\end{array}$ & Wage & Salary & $\begin{array}{c}\text { Overall } \\
\text { average }\end{array}$ \\
\hline Technical & avg. & 7.8 & 7.8 & 7.7 & $\mathbf{8 . 5}$ & $\mathbf{8 . 1}$ & $\mathbf{8 . 0}$ & 8.0 \\
documents & $N$ & 24 & 27 & 99 & 66 & 56 & 71 & \\
& $\sigma$ & 2.29 & 2.01 & 1.96 & 1.53 & 1.66 & 2.16 & \\
\hline Process & avg. & 7.0 & 7.1 & 6.9 & $\mathbf{7 . 7}$ & $\mathbf{7 . 3}$ & $\mathbf{7 . 4}$ & 7.2 \\
description & $N$ & 78 & 77 & 213 & 172 & 149 & 184 & \\
& $\sigma$ & 2.31 & 2.04 & 1.99 & 1.81 & 2.04 & 1.99 & \\
\hline \multirow{2}{*}{ Communication } & avg. & 7.0 & 6.9 & $\mathbf{7 . 4}$ & $\mathbf{7 . 8}$ & $\mathbf{7 . 5}$ & $\mathbf{7 . 4}$ & 7.3 \\
\& interaction & $N$ & 76 & 78 & 213 & 170 & 149 & 185 & \\
& $\sigma$ & 2.55 & 2.19 & 2.02 & 1.95 & 1.95 & 2.30 & \\
Quality \& & avg. & 6.8 & 6.9 & 6.7 & $\mathbf{7 . 3}$ & $\mathbf{7 . 2}$ & $\mathbf{7 . 0}$ & 7.0 \\
problem solving & $N$ & 77 & 78 & 214 & 171 & 147 & 184 & \\
\hline \multirow{2}{*}{ Test \& } & $\sigma$ & 2.34 & 1.83 & 2.10 & 2.04 & 2.10 & 2.16 & \\
measurement & avg. & 6.1 & 6.1 & 6.0 & $\mathbf{6 . 6}$ & $\mathbf{6 . 6}$ & $\mathbf{6 . 4}$ & 6.3 \\
& $N$ & 76 & 77 & 208 & 171 & 145 & 182 & \\
\hline
\end{tabular}

Table 2 Correlations with highest work experience level attained

\begin{tabular}{|c|c|c|c|c|c|c|c|c|}
\hline & & & Grammar & Listening & Reading & $\begin{array}{c}\text { Process } \\
\text { descrip- } \\
\text { tion } \\
\end{array}$ & $\begin{array}{c}\text { Test \& } \\
\text { measure- } \\
\text { ment }\end{array}$ & $\begin{array}{c}\text { Math. } \\
\text { expres- } \\
\text { sions } \\
\end{array}$ \\
\hline \multirow{4}{*}{$\begin{array}{c}\text { Highest work } \\
\text { level } \\
\text { experience }\end{array}$} & \multicolumn{2}{|c|}{$\begin{array}{l}\text { Spearman-rho } \\
\text { correlation coefficient }\end{array}$} & $-0.069 *$ & 0.079* & 0.078* & $0.074 *$ & 0.072* & $-0.067 *$ \\
\hline & \multicolumn{2}{|l|}{$N$} & 882 & 893 & 895 & 892 & 880 & 858 \\
\hline & \multirow{2}{*}{$\begin{array}{c}\text { Bootstrap } \\
95 \% \mathrm{CI}\end{array}$} & $\begin{array}{l}\text { Lower } \\
\text { value }\end{array}$ & -0.136 & 0.010 & 0.011 & 0.005 & 0.005 & -0.136 \\
\hline & & $\begin{array}{l}\text { Upper } \\
\text { value }\end{array}$ & -0.001 & 0.145 & 0.144 & 0.140 & 0.138 & 0.000 \\
\hline
\end{tabular}

* The correlation is significant on the 0.05 level (two-tailed)

The bootstrap results are based 10,000 bootstrap samples

There is evidently an inverse relationship between work experience level and both grammar as well as the technical language element mathematical expressions. Positive correlations are observed between work experience level and the core language modalities listening and reading as well as the aspects process description, and test and measurement.

\section{DISCUSSION}

The most prominent feature of the presented results is the universally high priority respondents assigned to technical vocabulary. This is perhaps a reflection of the prevalent viewpoint that the difference between general English and Technical English is 
essentially the lexis. The impression shared by the vast majority of those concerned would appear to be that there is a certain assemblage of words, the command of which will make the difference between effective technical communication and failure to communicate. Reality is perhaps somewhat more complex and being a competent communicator as an engineer actually requires an array of professional skills (Passow 2007, Riemer 2007).

Nonetheless, it appears logical that there must be a certain body of technical lexis which the engineer will find useful. Each ESP instructor is faced with the challenge, however, of attempting to determine what exactly that body of lexis is for their respective courses. This task is complicated by the great range of engineering fields, as well as the enormous degree of specialization within those fields themselves. The authors have recognized the complexity of this task and are in the process of developing a resource based on authentic, domain-specific technical texts. The completed resource is intended to serve as a future comprehensive source and guideline for Technical English instructors and learners.

A further key finding is that the respondents' valuation of language elements yields a rather clear result for the perceived importance of grammar. Figure 2 illustrated that the absolute ranking of grammar is comparably low to begin with, independent of work level experience. Moreover, the correlation results in Table 2 reveal that the valuation of grammar tends to decrease further with increasing work experience level.

The upshot of this outcome is that grammar appears to be generally unappreciated to begin with, and the results further reveal that increasing work experience has the effect of reducing the perceived priority of formal syntactic and morphological conventions. A likely explanation is that the respondents possess a Pareto principle approach to communication: after mastering the fundamentals of English grammar required to function sufficiently in the working environment, little to no additional diligence is invested in grammatical correctness. Respondents with work experience are aware that they can communicate effectively even in the absence of any significant consideration of inflection or syntax (cf. Björkman 2008). It is therefore completely feasible for a pragmatic ESP curriculum for intermediate students to focus more fully on language in context rather than on explicit instruction of syntax and morphology (Rahman 2015).

Turning to the four core modalities, writing has the lowest valuation by far, with numbers rivaling those of unappreciated grammar. As a productive modality, writing has perhaps the additional misfortune that it is time-consuming and does not benefit from the immediate feedback associated with speaking, where the reaction of one's conversational partner can signal directly whether communication has been successful. It is therefore not unlikely that many survey respondents associate writing with unrewarding time investment and little or no real-time feedback or feeling of accomplishment.

Further, inspection of the writing curve in Figure 2 reveals that its ranking not only is considered low by the respondents with a higher work experience level, but it tends to decline with greater work experience. This development sets the stage for the writing dilemma, the fact that writing is the modality at the focus of so very many ESP courses, often taking center stage at the expense of the other three modalities, but that this emphasis is not reflected by the on-the-job writing requirements reported by practitioners (Kaneko et al. 2009:5). The survey results show that if the ESP course curricula were to reflect the practitioners' perceived needs in the workplace, writing would take a clear backseat to the trio of listening, reading and speaking. 
The correlation results in fact show that for the respondents of this survey, listening and reading are two high-ranked modalities whose respective valuations tend to increase with higher work experience level. This implies that perhaps greater, practice-oriented attention should be devoted to these skills. This can be especially challenging with respect to the "Cinderella skill" of listening (Nunan 2002:238), since listening comprehension is subject to numerous factors in complex relationships (Bloomfield et al. 2010). The importance endowed upon reading is of course interesting in light of the high universal ranking of vocabulary. Reading and vocabulary are closely related to one another (Nation 2001), so addressing those related needs may go hand-in-hand.

Tables 1 and 2 provided insight into how the rankings of experienced and lessexperienced respondents differ. Among the goal-oriented language elements presented for assessment, process description and test and measurement both correlate with work experience level. The element technical documents, although it does not correlate with level of work experience, has average rankings which approach those for vocabulary and a trend to higher rankings for greater work experience level. These results express that experienced respondents recognize the practical relevance of these aspects whereas inexperienced respondents may lack the necessary context.

Let it be noted that the results show that there are also technical topics which receive not merely a lackadaisical but an actual outright negative response. The aspect mathematical expressions, which may sound relatively technical and thus spark some interest in the respondents, shows an inverse correlation with work experience level. Beyond teaching future engineers the absolute basics necessary for communication, there is apparently little to no need with this constituency to address mathematical terminology in any great detail.

Table 2 also includes results for two interpersonal communication aspects: communication and interaction as well as quality and problem solving. These are also rated higher on average by experienced respondents than by non-experienced ones. Presumably, this indicates that in practice the respondents have noted that such skills are also conducive to effective communication in the workplace.

\section{CONCLUSION}

The information compiled via this survey shows that there are distinct differences in the prioritization of certain language elements dependent on whether respondents have professional experience. Learners' previous experience as practitioners in the field is a readily available resource for ESP instructors when developing materials and curricula.

Students with work experience indicate the English language should be addressed in a practice-oriented context with less emphasis on prescription. Teaching listening warrants greater classroom resources than writing, and the high priorities given both reading and vocabulary open possibilities for their effective combination. At the same time, once a fundamental grasp of English syntax and morphology has been attained, the explicit instruction of grammar can be de-emphasized, outsourced or omitted in the ESP classroom, to instead focus on domain-specific applications and lexis. Finally, a practiceoriented ESP course should include both transaction-oriented technical components as well as communication-oriented interpersonal skills.

Awareness of the results of this study can help the ESP instructor design a course curriculum which experienced participants will recognize as relevant to their future 
careers. The practical applicability of the addressed skills will most likely be obvious to less-experienced course participants as well and thus impact motivation positively. The work experience-to-ESP curriculum development loop is one method for ensuring course content which adheres to practice and thus provides learners with real-life skills required for professional success.

\section{REFERENCES}

Björkman, Beyza. 2008. "English as the Lingua Franca of Engineering: The Morphosyntax of Academic Speech Events." Nordic Journal of English Studies 7, no.3: 103-122.

Bloomfield, Amber, Sarah C. Wayland, Elizabeth Rhoades, Allison Blodgett, Jared Linck, and Steven Ross. 2010. "What Makes Listening Difficult? Factors Affecting Second Language Listening Comprehension." Retrieved August 22, 2017 from http://www.dliflc.edu/wpcontent/uploads/2014/04/CASL_study_FINAL_Lit_Rev.pdf

Gürtler, Katherine, and Koenig, Eric. 2018 in press. "Mixed language learner levels in higher education as an adverse effect of post-secondary education de-tracking." Fremdsprachen und Hochschule, 92.

Kaneko, Emiko, William Rozycki, and Thomas Orr. 2009. "Survey of workplace English needs among computer science graduates." 2009 IEEE International Professional Communication Conference 1-6, DOI: 10.1109/IPCC.2009.5208704.

Nation, I. S. P. 2001. Learning vocabulary in another language. Cambridge: Cambridge University Press, 144

Nunan, D. 2002. "The changing face of listening." Methodology in language teaching: An anthology of current practice, ed. J. C. Richards and W. A. Renandya, 238-241. Cambridge: Cambridge University Press.

Passow, Honor J. 2007. "What Competencies should Engineering Programs Emphasize? A Meta-Analysis of Practitioners' Opinions Informs Curricular Design." Proceedings

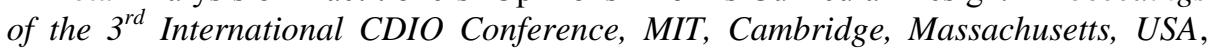
June 11-14.

Rahman, M. 2015. "English for Specific Purposes (ESP): A Holistic Review.” Universal Journal of Educational Research 3(1): 24-31, DOI: 10.13189/ujer.2015.030104

Riemer, Marc J. 2007. "Communication Skills for the 21st Century Engineer." Global Journal of Engineering Education 11, no.1: 89-100. 